\title{
Protective Effects of Liquiritin on the Brain of Rats with Alzheimer's Disease
}

\author{
X Huang ${ }^{1,2}$, Y Wang ${ }^{1}, \mathrm{~K}^{\text {Ren }}{ }^{1}$
}

\begin{abstract}
Background: Alzheimer's disease (AD) is a sort of nerve degenerative disease with clinical manifestation of memory damage and cognitive dysfunction. Its typical pathological change is the abnormal deposition of amyloid-beta $(A \beta)$.

Method: In this study, a rat $A D$ model with liquiritin (LQ) interference was established to observe the effects of $L Q$ on the $A D$ rats' behavioural memory and primary hippocampus cells.

Results: Liquiritin had the effect of improving the rats' learning and memory ability, enhancing the activity of catalase (CAT), superoxide dismutase (SOD) and glutathione peroxidase (GSH-Px) in rats' brain tissues, increasing the antioxidant ability, protecting the primary cultured hippocampal neurons and inhibiting the apoptosis induced by $A \beta_{25-35}$.

Conclusion: The protective effects of $L Q$ can be related to the enhancement of antioxidase activity and clearance of oxygen radicals.
\end{abstract}

Keywords: Alzheimer's disease, $\beta$-amyloid peptide, liquiritin, oxygen radicals, primary hippocampal neurons

\section{Efectos Protectores del Liquiritin en Cerebros de Ratas con la Enfermedad de Alzheimer \\ X Huang ${ }^{1,2}$, Y Wang ${ }^{1}, \mathrm{~K}^{\text {Ren }}{ }^{1}$}

\begin{abstract}
RESUMEN
Antecedentes: La enfermedad de Alzheimer (EA) es una especie de enfermedad degenerativa nerviosa con manifestaciones clínicas de daño de memoria y disfunción cognitiva. Su cambio patológico típico es el depósito anormal de beta-amiloide (Aß).

Método: En este estudio, se estableció un modelo de ratas con EA con interferencia de liquiritin (LQ) para observar los efectos de LQ en la memoria conductual y las células primarias del hipocampo de ratas con EA.

Resultados: El liquiritin tuvo como efectos: mejorar la capacidad de la memoria y el aprendizaje de las ratas; aumentar la actividad de catalasa (CAT), el superóxido dismutasa (SOD) y el glutatión peroxidasa (GSH-Px) en los tejidos del cerebro de ratas; aumentar la capacidad antioxidante; proteger las neuronas primarias hipocámpicas de cultivo; e inhibir la apoptosis inducida por $A \beta_{25-35}$.

Conclusión: Los efectos protectores de LQ pueden atribuirse a la mejora de la actividad antioxidasa y la depuración de los radicales de oxígeno.
\end{abstract}

Palabras claves: Enfermedad de Alzheimer, péptido $\beta$-amiloide, liquiritin, radicales de oxígeno, neuronas hipocámpicas primarias

West Indian Med J 2015; 64 (5): 468

\section{INTRODUCTION}

With the increase of an ageing population across the world, more and more old people are affected by Alzheimer's disease

From: ${ }^{1}$ Department of Pharmacology, Jilin Medical University, Jilin, China and ${ }^{2}$ Sinobioway Biomedicine Co. Ltd, Tianjin, China.

Correspondence: K Ren, Department of Pharmacology, Jilin Medical University, 5 Jilin Street, Fengman District, Jilin 132013, China. E-mail: hxd1221@163.com
(AD) to different degrees. As a sort of nerve degenerative disease, AD is clinically manifested by progressive memory damage and cognitive dysfunction (1). Although the aetiology of $\mathrm{AD}$ is not yet clear, a number of studies have demonstrated that the development of AD is mainly caused by the neuroinflammation induced by the deposition of amyloid-beta (A $\beta)$ which activated the microglia (2). The pathological state of AD patients' brain tissues is mainly manifested by senile plaque (SP) induced by deposition of $\beta$-amyloid peptide (A- 
$\beta$ ), the neurofibrillary tangle (NFT) induced by abnormal phosphorylation of intra-cellular proteins, the loss of pallium and cholinergic neuron, as well as amyloidosis in cerebral cortex arteries and arterioles, among which the abnormal deposition of $A \beta$ is the typical one. Amyloid-beta, activating the inflammatory reaction of microglia and astrocyte, induces the release of various inflammatory media with neurotoxic effects, resulting in a central lesion (3-5). Therefore, the toxicity of hippocampal neurons is regarded as the principal mechanism of AD.

Chinese herbs used to improve learning memory and prevent senile dementia are natural, multi-effective and usually less toxic than prescribed medications. A number of studies have been done on plant extracts for brain function improvement and senile dementia treatment. Liquorice root, a perennial herb of leguminosae, can be traced back to Shen Nong's herbs. Recently, the study of liquorice mostly focussed on its chemical composition of more than 300 flavonoids, 60 terpenoids, coumarins, 18 amino acids, various alkaloids, female hormones and organic acids etc in which the active constituents included the compounds of flavonoids, triterpenes and liquorice polysaccharides (6). The active constituent, liquiritin (LQ), has the effects of relieving pain and cough, and preventing inflammation, ulcer and allergic reaction; it also functions as an immunological enhancement, and the pharmacologic action may prevent viral hepatitis, cancer and AIDS (7-10). Liquiritin, belonging to the flavonones, is the potent constituent of Glycyrrhiza uralensis roots, $\mathrm{mol} \mathrm{fm}=\mathrm{C}_{21} \mathrm{H}_{22} \mathrm{O}_{9}$, $\mathrm{mol} \mathrm{wt}=418.13$ (11). Researchers have shown that LQ, with various bioactivities, is related to the antioxidant which has been clinically used in cardiovascular diseases, cancers and immune system disorders $(12,13)$. Due to the progression of pharma- co-activity studies of multidrug resistance, LQ has become one of the natural activity products attracting much attention.

In this study, a rat $\mathrm{AD}$ model with LQ interference was established using local injection of $A \beta_{25-35}$ into the lateral ventricle, to observe the effects of LQ on the AD rats' behavioural memory. Meanwhile, a rat primary cultured nerve cell model was set up to study the protective effects of LQ on primary cultured hippocampal cells, with an attempt to verify the effects of $\mathrm{LQ}$ on $\mathrm{AD}$ and its mechanisms from the perspective of molecular and cellular levels as well as the holo-zooscopy, and to provide experimental evidence for prevention and treatment of AD.

\section{SUBJECTS AND METHODS \\ Experimental animal}

Forty male SPF Sprague Dawley rats $(200 \pm 50 \mathrm{~g})$ and neonates (born within 24 hours, 50\% male and 50\% female) were purchased from the Experimental Animal Breeding Centre, Jilin University (Changchun, Jilin, China).

\section{Chemicals}

Liquiritin was purchased from the National Institute for the
Control of Pharmaceutical and Biological Products, lot no. 201002 (Beijing, China); $A \beta_{25-35}$ was gained from Sigma Co (USA). Superoxide dismutase (SOD), catalase (CAT) and glutathione peroxidase (GSH-Px) test kits were obtained from Jiancheng Biotech Co (Nanjing, Jiangsu, China). Iscove's Modified Dulbecco's Medium (IMDM) culture media, trypsin and fetal bovine serum were purchased from GIBCO Co (USA). N2, B27 and dissection liquid (15.1 mmo1/L glucose, $21.9 \mathrm{mmo} / \mathrm{L}$ sucrose, $136.9 \mathrm{mmo} / \mathrm{L} \mathrm{NaCl}, 5.4$ $\mathrm{mmol} / \mathrm{L} \mathrm{KCl}, 0.7 \mathrm{mmo} / / \mathrm{L} \mathrm{Na}_{2} \mathrm{HPO}_{4} \cdot 7 \mathrm{H}_{2} \mathrm{O}, 0.2 \mathrm{mmol} / \mathrm{L}$ $\mathrm{KH}_{2} \mathrm{PO}_{4}, \mathrm{pH}$ 7.2-7.4) were also obtained from GIBCO Co (USA).

\section{Instrumentation}

The UV-vis Spectrophotometer 722 was produced by Xin Mao Instruments Ltd Co (Shanghai). The semi-automatic Biochemical Analyzer GF-D600 was purchased from KaiAo Tech Ltd Co (Beijing). The microplate reader WD-9417A was obtained from Thermo Co (USA). The biosafety cabinet for cell culture was purchased from Biology Apparatus Co (Shanghai). The $\mathrm{CO}_{2}$ incubator for cell culture was produced by Helaeus Co (Germany). The flow cytometer was obtained from Becton Dickinson (USA).

Experimental grouping and preparation of AD rat model Sprague Dawley rats were randomly divided into five groups of eight rats each (normal control group, AD model group, high-dose LQ group [ $80 \mathrm{mg} / \mathrm{kg}$ ], moderate-dose LQ group [40 $\mathrm{mg} / \mathrm{kg}$ ] and low-dose LQ group [20 mg/kg]) who were orally gavaged with corn oil containing LQ for seven days. On the eighth day, after being anesthetized with $2 \%$ pentobarbital sodium $(40 \mathrm{mg} / \mathrm{kg})$, the rats were fixed to a brain stereotactic apparatus and parietal hairs were cut. After being disinfected with iodine, the cranium was drilled open at a spot which was $1.0 \mathrm{~mm}$ posterior to the anterior fontanel, $1.7 \mathrm{~mm}$ right to the median and $5 \mu \mathrm{A} \quad \beta_{25-35}(10 \mathrm{mmol} / \mathrm{L})$ was vertically injected into the cerebral dura mater; two minutes later, the microinjector was withdrawn and the incision was sewn up. The intragastric administration lasted for another 14 days (14).

\section{Morris water maze}

After the administration, Morris water maze $(150 \mathrm{~cm} \times 60 \mathrm{~cm}$ $\times 30 \mathrm{~cm}$ ) was used in an ethological test according to the previous reports (15-17). The maze was divided into four quadrants with a platform $(10 \mathrm{~cm})$ in the centre of quadrant 3 . The opaque black water (using black food additive) was $1 \mathrm{~cm}$ higher than the platform, without any other changes during the experiment.

\section{Spatial learning test}

The Morris water maze test was conducted on each group once a day for five days. On each day, the escape latency of the rats was recorded (no records for over 120 seconds). Rats who failed to find the platform within 120 seconds would be marked as 120 seconds, and forced to memorize the position by 
being kept on the platform for 10 seconds. On the $5^{\text {th }}$ day, test for position fixing and space exploration was made to calculate the residence time in quadrant 3 and crossing times of rats in order to check their memory.

\section{Antioxidative assay}

After the Morris water maze test was finished, all the rats were sacrificed. The rats were sacrificed by cervical dislocation and the brains were dissected and kept in pre-cold Dulbecco's Modified Eagle Medium (DMEM) basal medium. The brain tissue was rapidly taken out and kept on ice; $400 \mathrm{mg}$ of it was dissolved in saline to prepare the $10 \%$ tissue homogenate in an ice bath, and the homogenate was centrifuged at $4000 \mathrm{rpm}$ for 20 minutes to obtain the supernatant. The contents of malondialdehyde (MDA), SOD and GSH-Px in the supernatant were measured according to the instructions of the kits.

\section{Primary cell culture of hippocampal neurons in rats}

Primary hippocampal neurons were isolated from Sprague Dawley pups within 24 hours after they were born $(18,19)$. The hippocampus was isolated under a dissecting microscope and kept in pre-cold DMEM basal medium. Afterward, the hippocampus was cut into pieces of 1-3 $\mathrm{mm}$ in diameter, digested with $0.125 \%$ trypsin, filtered with 200 sieve mesh and centrifuged at $1000 \mathrm{rpm}$ for five minutes to collect the cell pellet. The cell pellet were resuspended with DMEM-F12 + 10\% fetal bovine serum and incubated at $37{ }^{\circ} \mathrm{C}$ with $5 \% \mathrm{CO}_{2}$. Twenty-four hours later, the medium was replaced with $\mathrm{DMEM} / \mathrm{F} 12+2 \% \mathrm{~B} 27$. Every three days, half of the medium was changed with new DMEM/F12 + 2\% B27. Cells were ready for use after seven days of culture.

\section{Immunofluorescence assay}

Hippocampal neurons were characterized with B-tubulin III through immunofluorescence assay $(20,21)$. After seven days of cultivation, primary hippocampal neurons were fixed with $4 \%$ paraformaldehyde, permeabilized with $0.3 \%$ Triton $X-100$ and then co-cultured with mouse anti-rat primary antibody (1:100 dilution) overnight at $4{ }^{\circ} \mathrm{C}$. TRITC-labelled anti-mouse secondary antibody was added on the second day after primary antibody was washed out three times with phosphate buffered saline (PBS). After two hours of incubation at room temperature, cells were photographed with a digital camera (AxioCam; Zeiss) coupled to an inverted microscope (AxioVert; Zeiss), using AxioVision 3.1 software (Zeiss).

\section{MTT assay and LDH level test}

After seven days of cultivation of the hippocampal neurons, $10 \mu \mathrm{mol} / \mathrm{L} \mathrm{A} \beta_{25-35}$ was injected into the model group. Liquiritin groups were given LQ $(0.1,1,10 \mu \mathrm{mo} 1 / \mathrm{L})$ and $10 \mu \mathrm{mol} / \mathrm{L}$ $\mathrm{A} \beta_{25-35}$, respectively with an interval of 24 hours. The same volume of saline was given to the control group. Seventy-two hours later, $5 \mu \mathrm{g} / \mathrm{mL}$ MTT was added, and the supernatant was removed after four hours incubation at $37^{\circ} \mathrm{C}$. The reaction was stopped by $150 \mathrm{ul}$ dimethyl sulfoxide (DMSO). Optical density (OD) was measured at $570 \mathrm{~nm}$ and the survival rate was calculated (22). Following the instructions of the lactate dehydrogenase (LDH) test kit, culture solution was taken to detect the absorbance at $440 \mathrm{~nm}$ and to measure the $\mathrm{LDH}$ level(23).

\section{Apoptosis detection assay}

The hippocampal neurons, cultivated for seven days and induced by $\mathrm{A} \beta_{25-35}$ for 48 hours, were washed by PBS and digested by $0.125 \%$ trypsin. The cells were put into $200 \mu \mathrm{l}$ buffer, after 10 minutes staining with annexin V-FITC/PI (24), to be detected by flow cytometer in order to calculate the apoptosis ratio.

\section{Statistical analysis}

All experiments were repeated at least three times (mean \pm SEM). Significance $(p<0.05)$ was determined by either a oneway or two-way analysis of variance (ANOVA) with a post hoc mean comparison performed by Newman Keuls multiple range test. A Student's $t$-test was used when the means of the two groups were compared.

\section{RESULTS}

\section{Spatial learning and memory test}

Compared with those in the model group, the escape latency of the LQ group (40 and $80 \mathrm{mg} / \mathrm{kg} \cdot \mathrm{d}$ ) was significantly shortened, and crossing times and residence time in quadrant 3 were increased $(p<0.05) p<0.001)$ [Table 1]. The results suggest that LQ may improve the rats' spatial learning and memory ability.

Table 1: Effects of liquiritin (LQ) on spatial learning and memory of Alzheimer's disease rats in Morris test

\begin{tabular}{llll}
\hline Groups & Escape latencies (s) & $\begin{array}{c}\text { Time spent in } \\
\text { quadrant 3 (s) }\end{array}$ & $\begin{array}{c}\text { Number of } \\
\text { crossing } \\
\text { platform }\end{array}$ \\
\hline Control & $34.31 \pm 14.25$ & $37.95 \pm 18.98$ & $6.41 \pm 3.32$ \\
Model & $56.67 \pm 38.75^{* *}$ & $23.87 \pm 24.23^{* *}$ & $2.74 \pm 1.08^{* *}$ \\
LQ $(20 \mathrm{mg} / \mathrm{kg} \cdot \mathrm{d})$ & $43.42 \pm 27.57$ & $24.87 \pm 21.04$ & $3.94 \pm 1.58$ \\
$\mathrm{LQ}(40 \mathrm{mg} / \mathrm{kg} \cdot \mathrm{d})$ & $39.15 \pm 23.45^{\#}$ & $38.86 \pm 25.86^{\#}$ & $3.82 \pm 2.27^{\# \#}$ \\
$\mathrm{LQ}(80 \mathrm{mg} / \mathrm{kg} \cdot \mathrm{d})$ & $38.71 \pm 22.15^{\#}$ & $37.92 \pm 20.84^{\#}$ & $4.25 \pm 2.69^{\# \#}$ \\
\hline${ }^{*} p<0.05,{ }^{* * *} p<0.01$ v control group ${ }^{*} p<0.05,{ }^{* \#} p<0.01$ &
\end{tabular}

\section{Antioxidative assay}

As shown in Table 2, compared with those in the model group, CAT and SOD contents of rats' brain tissues in the LQ groups were increased, and CAT, SOD and GSH-Px activity in the LQ groups (40 and $80 \mathrm{mg} / \mathrm{kg} \cdot \mathrm{d})$ was higher statistically $(p<0.05$, $p<0.01)$.

After seven-day culture with non-serum nerve solution, the original round hippocampal neurons were interlaced like a net with many projections, the cells of which grew into the typical fusiform and cone shape. Microscopically, these cells were positively stained with the heterologous protein $\beta$-tubulin III (Fig. 1), which determined the neuron cells. 
Table 2: Effects of liquiritin (LQ) on the contents of CAT, SOD and GSHPx in brain tissues of Alzheimer's disease rats $( \pm s ; n=10)$

\begin{tabular}{|c|c|c|c|}
\hline Groups & $\begin{array}{c}\text { CAT } \\
(\mathrm{nmol} / \mathrm{mgp})\end{array}$ & $\begin{array}{c}\text { SOD } \\
\text { (U/mgp) }\end{array}$ & $\begin{array}{l}\text { GSH-Px } \\
\text { (U/mgp) }\end{array}$ \\
\hline Control & $1.87 \pm 0.57$ & $96.28 \pm 27.35$ & $149.78 \pm 69.72$ \\
\hline Model & $0.94 \pm 0.53^{*}$ & $57.53 \pm 20.81^{* *}$ & $98.94 \pm 55.31^{*}$ \\
\hline LQ $(40 \mathrm{mg} / \mathrm{kg} \cdot \mathrm{d})$ & $1.05 \pm 0.61^{\#}$ & $71.43 \pm 25.75^{\#}$ & $103.45 \pm 41.48$ \\
\hline LQ $(80 \mathrm{mg} / \mathrm{kg} \cdot \mathrm{d})$ & $1.31 \pm 0.22^{\#}$ & $88.32 \pm 24.11^{\#}$ & $129.78 \pm 31.11^{\#}$ \\
\hline LQ $(160 \mathrm{mg} / \mathrm{kg} \cdot \mathrm{d})$ & $1.54 \pm 0.34^{\#}$ & $91.24 \pm 20.33^{\# \#}$ & $137.56 \pm 57.24^{\sharp}$ \\
\hline
\end{tabular}

${ }^{*} p<0.05,{ }^{* *} p<0.01$ vs control group; ${ }^{\#} p<0.05,{ }^{\# \#} p<0.01$ vs model group CAT: catalase; SOD: superoxide dismutase; GSH-Px: glutathione peroxidase
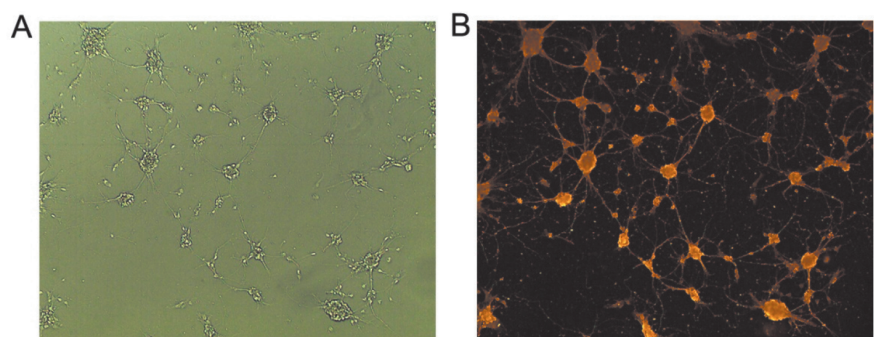

Fig. 1: Cell forms of hippocampal neurons. A: Cell forms of hippocampal neurons by light microscope; B: Cell forms of hippocampal neurons marked by $\beta$-tubulin III by immunochemical observation.

\section{Protection of hippocampal neurons by LQ}

According to MTT test, compared with that in the model group, OD in LQ $(1 \mu \mathrm{mol} / \mathrm{mL}, 10 \mu \mathrm{mol} / \mathrm{mL})$ was statistically significantly higher $(p<0.05)$, which indicated that LQ may reduce the injury induced by $\mathrm{A} \beta_{25-35}$. The LDH test showed that LDH activity in the supernatant of LQ $(1 \mu \mathrm{mol} / \mathrm{mL}, 10$ $\mu \mathrm{mol} / \mathrm{mL})$ was significantly lower statistically $(p<0.05)$ as compared with that in the model group, which suggested that LQ has positive effects on the reduction of injuries of primary hippocampal neurons (Fig. 2).
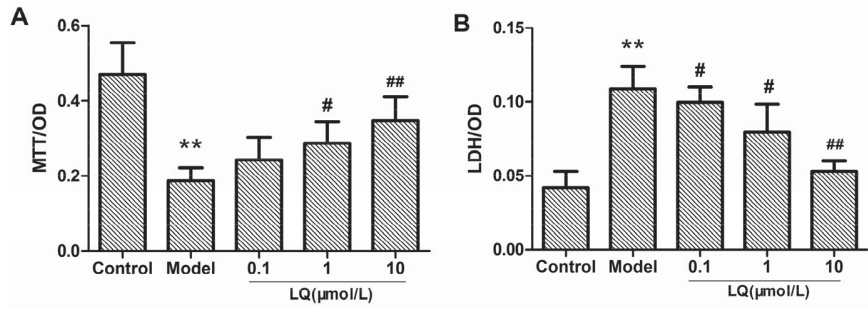

Fig. 2: Protective effects of liquiritin (LQ) on the primary cultured hippocampal neurons induced by $\mathrm{A} \beta_{25-35}(\mathrm{n}=3, \pm \mathrm{s})$. A: optical density (OD) in MTT test; B: OD in lactate dehydrogenase (LDH) test. ${ }^{*} p<0.05,{ }^{* *} p<0.01$ vs control group; ${ }^{\#} p<0.05,{ }^{\# \#} p<0.01$ vs model group

\section{Inhibitory effect of LQ on apoptosis of hippocampal neu- rons}

Compared with that in the model group, the cell distribution of apoptosis was gradually decreased in the LQ group (1 $\mu \mathrm{mol} / \mathrm{mL}, 10 \mu \mathrm{mol} / \mathrm{mL}$ ), with the apoptosis percentage as $15.37 \pm 1.60 \%$ and $14.30 \pm 1.78 \%$, which was statistically significant ( $p<0.01, p<0.01$ ) [Fig. 3]. This implied that the
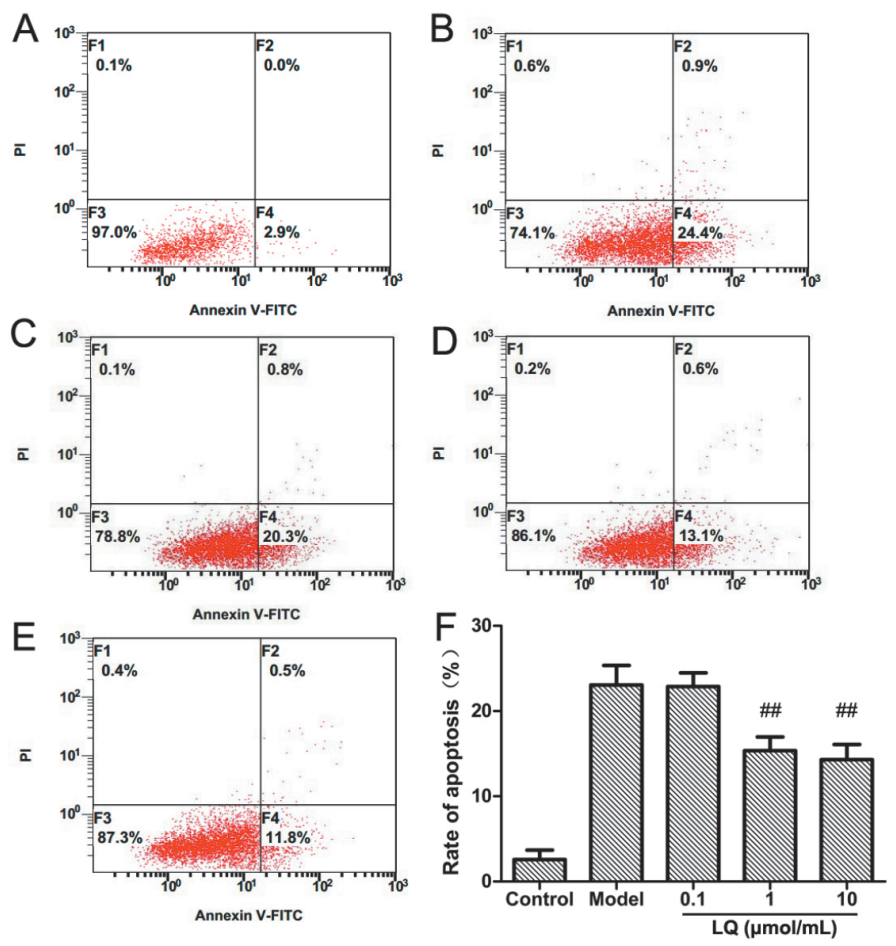

Fig. 3: Effects of liquiritin (LQ) on the apoptosis ratio of primary cultured hippocampal neurons induced by $\mathrm{A} \beta_{25-35}(\mathrm{n}=3, \pm \mathrm{s})$. A: Control; B: Model; C: LQ (40 mg/kg $\cdot d)$; D: LQ $(80 \mathrm{mg} / \mathrm{kg} \cdot \mathrm{d})$; E: LQ (160 $\mathrm{mg} / \mathrm{kg} \cdot \mathrm{d}) ; \mathrm{F}$ : percentage of apoptosis.

apoptosis of hippocampal neurons induced by $\mathrm{A} \beta_{25-35}$ was inhibited by LQ.

\section{DISCUSSION}

Amyloid beta, as the essential component for the cerebral pathological feature senile plaque of AD patients (25), showed great neurotoxicity and induced apoptosis through various ways, such as oxidative stress (26). In our study, an AD model was made by injecting $A \beta_{25-35}$ and deposition of $A \beta$. The spatial learning memory of rats was tested by the Morris water maze test. The model in this study simulated the ethological effects of AD learning and memory disorders. According to the Morris test, the escape latency of rats in the $A \beta$ group was longer than that in the control group. Liquiritin has the effects of reducing the escape latency of $\mathrm{AD}$ rats and increasing the crossing times and residence time in quadrant 3 , which indicated that the learning memory ability of $\mathrm{AD}$ rats could be improved by LQ and implied favourable therapeutic action of LQ on AD. With the intervention of LQ, the activity of CAT, SOD and GSH-Px in brain tissues of AD rats was significantly increased, which demonstrated the effects of SOD on clearance of free radicals and function of injuries (27). The excess peroxide and the free radicals were cleared, respectively by CAT in peroxisome $(28,29)$ and GSH-Px in mitochondria $(30)$. The results in our study suggested that LQ was effective in increasing the activity of CAT, SOD, GSH-Px, clearing the free radicals and protecting the oxidative damage induced by $\mathrm{A} \beta$. 
In this study, $\mathrm{A} \beta_{25-35}$ was applied to the primary hippocampal neurons to simulate the prophase pathological process of AD (31). MTT assay and LDH level test showed the metabolic activity and cell integrity $(32,33)$. The results indicated the protective effects of LQ on nerve cells since MTT value was increased by LQ and LDH level was decreased by it. The inhibitive effects of LQ on the apoptosis of nerve cells induced by $\mathrm{A} \beta_{25-35}$, which were tested by annexin V-FITC/PI FCM, can be one of the protective mechanisms of LQ on neurons.

\section{REFERENCES}

1. Braidy N, Muñoz P, Palacios AG, Castellano-Gonzalez G, Inestrosa NC, Chung RS et al. Recent models for Alzheimer's disease: clinical implications and basic research. J Neural Transm 2012; 119: 173-95.

2. Neher JJ, Neniskyte U, Brown GC. Primary phagocytosis of neurons by inflamed microglia: potential roles in neurodegeneration. J Front Pharmacol 2012; 3: 27.

3. Hemachander C, Valérie V, Haitian Z, Roman S, Yousef A-A, Peter D et al. Resveratrol mitigates lipopolysaccharide and AB-mediated microglial inflammation by inhibiting TLR4/NF- $\mathrm{KB} / \mathrm{STAT}$ signaling cascade. J Neurochem 2012; 120: 461-72.

4. Casal C, Serratosa J, Tusell JM. Effects of beta-AP peptides on activation of the transcription factor NF-kappa B and in cell proliferation in glial cell cultures. J Neurosci Res 2004; 48: 315-23.

5. Newman M, Musgrave IF, Lardelli M. Alzheimer disease: amyloidogenesis, the presenilins and animal models. Biochim Biophys Acta 2007; 1772: 285-97.

6. Guo P, Sun Z, Liu W, Chen L, Du Y, Wei X. Correlation analysis between the rate of respiration in the root and the active components in licorice (Glycyrrhiza uralensis). Exp Ther Med 2014; 7: 270-4.

7. Zhao Z, Wang W, Guo H, Zhou D. Antidepressant-like effect of liquiritin from Glycyrrhiza uralensis in chronic variable stress induced depression model rats. Behav Brain Res 2008; 194: 108-13.

8. Wang W, Hu X, Zhao Z, Liu P, Hu Y, Zhou J et al. Antidepressant-like effects of liquiritin and isoliquiritin from Glycyrrhiza uralensis in the forced swimming test and tail suspension test in mice. Prog Neuropsychopharmacol Biol Psychiatry 2008; 32: 1179-84.

9. Chen Z, Wang J, Liu R, Ren J, Wen L, Chen X et al. Liquiritin potentiate neurite outgrowth induced by nerve growth factor in PC12 cells. Cytotech 2009; 60: 125-32.

10. Sun Y, Tang Y, Wu A, Liu T, Dai X, Zheng Q et al. Neuroprotective effect of liquiritin against focal cerebral ischemia/reperfusion in mice via its antioxidant and antiapoptosis properties. J Asian Nat Prod Res 2010; 12: 1051-60.

11. Wang Y, Yao Y, An R, You L, Wang X. Simultaneous determination of puerarin, daidzein, baicalin, wogonoside and liquiritin of GegenQinlian decoction in rat plasma by ultra-performance liquid chromatography-mass spectrometry. J Chromatogr B Analyt Technol Biomed Life Sci 2009; 877: 1820-6.

12. Brann DW, Dhandapani K, Wakade C, Mahesh VB, Khan MM. Neurotrophic and neuroprotective actions of estrogen: basic mechanisms and clinical implications. Steroids 2007; 72: 381-405.

13. Chen LM, Lü QJ, Satoshi I, Bian GX, Chen ZH, Wen LQ. Establishment of a reporter gene-based cell screening model for discovering new agonists of estrogen receptor beta subtype. Yao Xue Xue Bao 2006; 41: 721-6.

14. Yamada K, Nabeshima T. Animal models of Alzheimer's disease and evaluation of anti-dementia drugs. Pharmacol Ther 2000; 88: 93-113.
15. Pasinetti GM. From epidemiology to therapeutic trials with anti-inflammatory drugs in Alzheimer's disease: the role of NSAIDs and cyclooxygenase in beta-amyloidosis and clinical dementia. J Alzheimers Dis $2002 ; 4:$ : 435-45.

16. Colm C, Donal TS. Non-steroidal anti-inflammatory drugs and cognitive function: are prostaglandins at the heart of cognitive impairment in dementia and delirium? J Neuroimmune Pharmacol 2012; 7: 60-73.

17. Rudolph ET. Novel therapeutics for Alzheimer's disease. Neurotherapeutics 2008; 5: 377-80.

18. Hsin H, Kim MJ, Wang CF, Sheng M. Proline-rich tyrosine kinase 2 regulates hippocampal long-term depression. J Neurosci 2010; 30: 11983-93.

19. Lu H, Pang W, Hu YD, Yang HP, Huang CY, Jiang YG. Effects of intracellular zinc depletion on the expression of VDAC in cultured hippocampal neurons. Nutr Neurosci 2011; 14: 80-7.

20. Kellner Y, Gödecke N, Dierkes T, Thieme N, Zagrebelsky M, Korte M. The BDNF effects on dendritic spines of mature hippocampal neurons depend on neuronal activity. Front Synaptic Neurosci 2014; 20: 5.

21. Bian XH, Zhang H. Effect of acupoint catgut-embedding therapy on changes of structure of hippocampal neurons in senile chronic stress rats. Zhen Ci Yan Jiu, 2014; 39: 35-9.

22. Yu L, Jiang R, Su Q, Yu H, Yang J. Hippocampal neuronal metal ion imbalance related oxidative stress in a rat model of chronic aluminum exposureand neuroprotection of meloxicam. Behav Brain Funct 2014; 10: 6 .

23. Cao BY, Yang YP, Luo WF, Mao CJ, Han R, Sun X et al. Paeoniflorin, a potent natural compound, protects $\mathrm{PC} 12$ cells from $\mathrm{MPP}^{+}$and acidic damage via autophagic pathway. J Ethno 2010; 131: 122-9.

24. Wang L, Gao C, Yao S, Xie B. Blocking autophagic flux enhances matrine-induced apoptosis in human hepatoma cells. Int J Mol Sci 2013; 14: $23212-30$

25. Escribano L, Simón AM, Gimeno E, Cuadrado-Tejedor M, López de Maturana R, García-Osta A et al. Rosiglitazone rescues memory impairment in Alzheimer's transgenic mice: mechanisms involving a reduced amyloid and tau pathology. Neuropsycho 2010; 35: 1593-604.

26. Cui X, Zuo P, Zhang Q, Li X, Hu Y, Long J et al. Chronic systemic Dgalactose exposure induces memory loss, neuro degeneration, and oxidative damage in mice: protective effects of R-alpha-lipoic acid. J Neurosci Res 2006; 84: 647-54.

27. Gotloib L. Mechanisms of cell death during peritoneal dialysis. A role for osmotic and oxidative stress. Contrib Nephrol 2009; 163: 35-44.

28. Yuan Y, Guo Q, Ye Z, Pingping X, Wang N, Song Z. Ischemic postconditioning protects brain from ischemia/reperfusion injury by attenuating endoplasmic reticulum stress-induced apoptosis through PI3K-Akt pathway. Brain Res 2011; 1367: 85-93.

29. Karuna T, Uma B, Mandar Z, Rahul S. Antihyperglycemic and antioxidant activity of Clitorea ternatea Linn. on streptozotocin-induced diabetic rats. Ayu 2013; 34: 433-9.

30. Khan MI, Khan MR. Gastroprotective potential of Dalbergia sissoo Roxb. stem bark against diclofenac-induced gastric damage in rats. Osong Public Health Res Perspect 2013; 4: 271-7.

31. Calvillo M, Diaz A, Limon DI, Mayoral MA, Chánez-Cárdenas ME, Zenteno $\mathrm{E}$ et al. Amyloid- $\beta$ (25-35) induces a permanent phosphorylation of HSF-1, but a transitory and inflammation-independent overexpression of Hsp-70 in C6 astrocytoma cells. Neuropeptides 2013; 47: 339-46.

32. Darakhshan S, Bidmeshkipour A, Khazaei M, Rabzia A, Ghanbari A . Synergistic effects of tamoxifen and tranilast on VEGF and MMP-9 regulation in cultured human breast cancer cells. Asian Pac J Cancer Prev 2013; 14: 6869-74.

33. Ramyaa P, Krishnaswamy R, Padma VV. Quercetin modulates OTA-induced oxidative stress and redox signalling in HepG2 cells - up regulation of Nrf2 expression and down regulation of $\mathrm{NF}-\kappa \mathrm{B}$ and COX2. Biochim Biophys Acta 2014; 1840: 681-92. 